\title{
Human resource management practices in a medical complex in the Eastern Cape, South Africa: Assessing their impact on the retention of doctors
}

\author{
B Longmore, MB ChB; L Ronnie, $\mathrm{PhD}$ \\ Graduate School of Business, University of Cape Town, South Africa
}

Corresponding author: L Ronnie (linda.ronnie@gsb.uct.ac.za)

Background. Human resource management (HRM) practices have the potential to influence retention of doctors in the public health sector. Objective. To explore the key human resource (HR) practices affecting doctors in a medical complex in the Eastern Cape, South Africa. Methods. We used an open-ended questionnaire to gather data from 75 doctors in this setting.

Results. The most important HR practices were paying salaries on time and accurately, the management of documentation, communication, HR staff showing that they respected and valued the doctors, and reimbursement for conferences and special leave requests. All these practices were judged to be poorly administered. Essential HR characteristics were ranked in the following order: task competence of HR staff, accountability, general HR efficiency, occupation-specific dispensation adjustments and performance management and development system efficiency, and availability of HR staff. All these characteristics were judged to be poor.

Conclusion. HRM practices in this Eastern Cape medical complex were inadequate and a source of frustration. This lack of efficiency could lead to further problems with regard to retaining doctors in public sector service.

S Afr Med J 2014;104(5):368-371. DOI:10.7196/SAMJ.7751

The Eastern Cape Province of South Africa (SA) is described as having a healthcare crisis. Failure to pay salaries to staff and shortages of medicines and basic medical supplies have been cited as manifestations of what were believed to be far-reaching systemic failures in the financing and management of services in the province. ${ }^{[1]}$ At the heart of this crisis lie two key issues, namely poor management and severe staff shortages.

It may be obvious that sound human resource management (HRM) of healthcare workers (HCWs) is critical for the functioning of a healthcare system, but the importance of HRM seems to be overlooked in some SA settings. One of the most concerning factors facing healthcare in 
the Eastern Cape is the province's struggle to retain doctors in the hospital system. Although this retention issue seems to be multifaceted the role HRM appears to play at an Eastern Cape health institution badly affected by staff shortages is of particular concern.

The Eastern Cape medical complex, like many others, has recently experienced severe staffing difficulties. Delayed payment of salaries to critically important healthcare employees was quoted as one of the reasons why doctors and other health professionals abandon their public healthcare posts. ${ }^{[2]}$ This situation exposes the relationship between HRM and retention, and highlights the need to assess and understand it.

Although the present Minister of Health has recognised that human resource (HR) capacity is a problem facing the health system in general and has included its improvement in the Department of Health's 10 -point strategy plan, ${ }^{[3]}$ there is a concern that insufficient effort is being channelled to address the issues timeously. As recently as May 2012, the Minister suggested a possible intervention to address the state of affairs in the Eastern Cape, ${ }^{[4]}$ which has 2.97 public doctors per 10000 people, a ratio among the lowest in the country. ${ }^{[5]}$ This situation appears to have been deteriorating over the past few years, as highlighted in the poor publicity the province has attracted.

\section{Objectives}

The purpose of this research was to explore the potential impact of various HRM practices on the retention of public sector doctors in the Eastern Cape. The research has made it possible not only to appreciate the importance of the various practices and their characteristics, but also to understand perceptions of how these practices are being executed in an SA setting that is facing significant retention challenges. We suggest that an improved understanding of the HRM challenges in this public hospital setting may be utilised at a national level to facilitate retention of doctors in the SA public sector as a whole.

\section{Methods}

An Eastern Cape hospital complex with staffing difficulties was identified as a setting within which to conduct the study. A mixed-methods approach was adopted that combined both qualitative and quantitative strategies. This facilitated the exploratory and descriptive study to be conducted in the cohort of affected doctors.

A three-stage process was followed. The first stage consisted of a review of the literature and revealed a paucity of studies surrounding HRM practices and their impact on retention of HCWs in the public health sector. Studies on factors underpinning HCW migration ${ }^{[6]}$ and HCW motivation ${ }^{[7,8]}$ were therefore drawn on to begin the research process. A second phase consisting of semi-structured interviews with the hospital complex's clinical heads of department was then undertaken to shed light on the intended role of the HR department and reveal the potential impact of HR practices from a managerial point of view.

With the above information and the findings from the literature, the third and final part of the research, a survey questionnaire, was designed. Following a small pilot study, the survey was administered anonymously to more than 250 doctors in the complex via an electronic platform following an email and SMS request. Responses to the survey were gathered over a 2-week period. During this time, the full doctor complement received reminders via e-mail and SMS to complete the survey. At the time of closing, 93 responses were entered; however, only 75 were complete, giving a $30 \%$ response rate from an estimated sample population of 250 .

The open-ended questionnaire separated HRM into two distinct parts, the first being HR practices and the second HR characteristics. After respondents provided demographic data, they were asked to rank five identified HR practices in order of importance. This was followed by an open question requesting an explanation of the respondents' highest-ranked practice. The doctors were then asked to rate the performance of the complex's HR department in the five practices. This template was repeated for the second theme, the five HR characteristics.

\section{Results}

Table 1 shows the demographic characteristics of the survey respondents. There were marginally more males than females and the majority of responses came from the age group 25 - 32 years ('Generation Y'). Medical officers formed the largest group of respondents (31\%), closely followed by interns and then community service doctors. Almost $74 \%$ of the survey respondents reported that they had worked at the complex for less than 5 years.

Generational classification was intentionally used for the age category selection to determine whether there were generational variations in the survey responses. Generation Y, or individuals from 25 to 32 years of age, formed the largest group of respondents (almost 70\%). This is interesting for a number of reasons. If the sample population is representative of the whole, a significant portion of the complex's medical workforce is made up of a generation that is proving difficult to manage. ${ }^{[9]}$ The resounding agreement in the literature regarding this difficulty indicates a growing challenge. Seen as the most high-maintenance group to enter the workforce, Generation $\mathrm{Y}$ are multi-taskers who have high expectations of both themselves and their employers. ${ }^{[10]}$ This poses attraction, motivation and retention challenges for the public health sector.

\section{Key HR practices - importance ranking (Table 2)}

Most doctors felt that paying them on time and accurately was the most important HR practice. There was much emotion surrounding remuneration inconsistencies and resulting financial insecurity, doctors feeling that it is simply not acceptable to fail to pay salaries on time. Documentation management and communication, both essential HR components, were ranked by responding doctors as second and third, respectively. Like salary errors, documentation loss and failures of communication were detested, and resulted in extreme levels of frustration.

Ranking fourth, being respected and valued by $H R$ staff was something that doctors felt was less important than the basic HR functions being undertaken

\begin{tabular}{ll}
$\begin{array}{l}\text { Table 1. Demographic characteristics } \\
\text { of respondents }\end{array}$ \\
\hline Variable & $\%$ \\
\hline Gender (male) & 60 \\
Age (years) & \\
25 - 32 & 68 \\
$33-50$ & 17 \\
$51-66$ & 11 \\
$\geq 67$ & 4 \\
Current position & \\
Intern & 28 \\
Community service & 19 \\
Medical officer & 30 \\
Registrar & 8 \\
Consultant & 15 \\
Duration of service at the complex \\
(years) \\
$<2$ \\
$\geq 2-5$ \\
$\geq 5$ - $\leq 10$ & 39 \\
$>10$ & 10 \\
& \\
& \\
&
\end{tabular}


properly. However, one doctor ranked this practice as first, stating, 'If the staff of HR respected and valued us, then they would pay us on time, keep our documents safe, strive to communicate effectively and place priority on our continued education.' The last HR practice, reimbursement for courses/conferences attended and special leave requests, although playing a critical role in both the doctors' development and the clinical functioning of the hospital complex, was ranked by doctors as least important. Like value and respect, it was trumped by the importance of timeous salary payment, documentation management and communication.

\section{Respondents' rating of the complex's key HR practices (Table 2)}

Both the quantitative and qualitative data collected showed that this Eastern Cape health complex failed in all five key HR practices. Accurate payment of salaries, with its critical role in employee security, was mentioned as problematic 45 times in the open responses. Many doctors had been victims of late or inaccurate payment, and numerous others feared non-payment on a monthly basis. Quantitative data revealed a spread of responses describing a practice that is completely unacceptable in the private sector.

Document management and communication efforts by the complex HR staff

Table 2. Importance ranking and respondents' rating of HR practices

\begin{tabular}{|c|c|c|c|c|c|}
\hline \multirow{2}{*}{$\begin{array}{l}\text { Importance } \\
\text { ranking }\end{array}$} & \multirow{2}{*}{ HR practice } & \multicolumn{4}{|c|}{ Respondents' rating, \% } \\
\hline & & Unacceptable & Acceptable & Good & Very good \\
\hline 1 & $\begin{array}{l}\text { Monthly salary paid on } \\
\text { time }\end{array}$ & 16 & 36 & 28 & 20 \\
\hline 2 & $\begin{array}{l}\text { An adequate document } \\
\text { collection, filing and } \\
\text { storage system }\end{array}$ & 85 & 15 & 0 & 0 \\
\hline 3 & $\begin{array}{l}\text { Good communication, } \\
\text { e.g. regarding post } \\
\text { availability, status of } \\
\text { requests made to the } \\
\text { department, and the } \\
\text { whereabouts of submitted } \\
\text { documents }\end{array}$ & 84 & 15 & 1 & 0 \\
\hline 4 & $\begin{array}{l}\text { To be respected and } \\
\text { valued by HR staff and } \\
\text { receive friendly and } \\
\text { helpful service }\end{array}$ & 64 & 32 & 4 & 0 \\
\hline 5 & $\begin{array}{l}\text { Reimbursement for } \\
\text { courses/conferences } \\
\text { attended, and processing } \\
\text { of special leave requests }\end{array}$ & 57 & 39 & 4 & 0 \\
\hline
\end{tabular}

were rated by $84 \%$ of doctors as dismal. Doctors cited numerous cases of repeated document loss, identity fraud and failure of communication.

Sixty-four per cent of doctors felt that they were not respected and valued by HR staff. This was corroborated by the qualitative responses in both the interviews and the survey. As mentioned above, the crucial administration regarding continuing education and career development, although ranked least important, received a vote of failure from $57 \%$ of responding doctors.

\section{Essential HR characteristics}

The second theme of HR characteristics was dominated by doctors ranking task competence of HR staff as the most important factor. It was clear that HR staff did not exhibit competence when dealing with their concerns, causing annoyance and frustration. This characteristic was followed in the importance ranking by accountability, a characteristic that doctors perceived to be a driver of excellence and quality.

The third-ranked characteristic that doctors felt it was important for HR staff to exhibit was general process efficiency. Responses emphasised that process efficiency enables timeous handling of critical activities such as application processing, problem identification and failure resolution. This importance was confirmed by the fourth-ranked characteristic, salary adjustment efficiency relating to the occupation-specific dispensation (OSD) and the performance management and development system (PMDS). When their salary adjustments were correctly carried out, doctors felt that their concerns in this regard had been adequately attended to by the HR department. Availability of $\mathrm{HR}$ staff was the fifth-ranked characteristic. As a result of their substantial clinical load,

Table 3. Importance ranking of HR performance characteristics and respondents' rating

\begin{tabular}{|c|c|c|c|c|c|c|}
\hline \multirow{2}{*}{$\begin{array}{l}\text { Importance } \\
\text { ranking }\end{array}$} & \multirow[b]{2}{*}{ HR performance characteristics } & \multicolumn{5}{|c|}{ Respondents' rating, \% } \\
\hline & & Unacceptable & Acceptable & Good & Very good & Not applicable \\
\hline 1 & Task competence of HR staff & 77 & 19 & 3 & 0 & 1 \\
\hline 2 & $\begin{array}{l}\text { Accountability of HR staff for queries made or } \\
\text { documents submitted }\end{array}$ & 82 & 17 & 1 & 0 & 0 \\
\hline 3 & General HR process efficiency & 87 & 12 & 1 & 0 & 0 \\
\hline 4 & $\begin{array}{l}\text { OSD salary level adjustments and PMDS } \\
\text { efficiency }\end{array}$ & 51 & 27 & 12 & 1 & 9 \\
\hline 5 & $\begin{array}{l}\text { Availability of HR staff during tea and lunch } \\
\text { breaks }\end{array}$ & 65 & 28 & 3 & 0 & 4 \\
\hline
\end{tabular}


doctors struggled to visit the HR department at times other than their tea and lunch breaks, during which HR staff were frequently unavailable.

\section{Rating the complex's HR performance characteristics (Table 3)}

Seventy-seven per cent of doctors rated the task competence of HR staff as unacceptable, making it clear that a deficiency existed in this core function. Many doctors felt that this was the greatest failure of the HR department and believed that the solution to the problems of poor HRM lay in the training of HR staff. This failure impacted on doctors on a daily basis through fundamental remuneration uncertainty, and was noticeably frustrating for them.

The second- and third-ranked characteristics, accountability and general process efficiency, were very poorly rated by the responding doctors. Alarmingly, these characteristics were perceived to be unacceptable by $82 \%$ and $87 \%$ of doctors, respectively. There were many examples of doctors being affected by these failures, corroborated by a comment from a senior doctor: 'I have examples of doctors who applied to work in my department who, when finally offered a post, had already been working in an alternative post elsewhere for over 6 months.

OSD and PMDS performance, although lower down on the importance ranking, was rated as unacceptable by $51 \%$ of doctors. The responses indicate that this crucial tool for incentivising doctors is now more of a frustration for them. Lastly, the non-availability of HR staff during tea and lunch breaks received a verdict of 'unacceptable' from $65 \%$ of respondents.

\section{Discussion}

All HR practices in the complex studied are in need of substantial improvement. Based on the qualitative responses and the performance ratings, doctors in the complex are clearly frustrated by the poor levels of HRM. This frustration is unfortunately bound to have negative effects on the institution's capacity to retain medical staff. It is clear that the HRM characteristics identified are all being performed unacceptably poorly, despite their relative rankings of importance. Doctors were overwhelmingly dismayed regarding the performance of HR staff, with virtually all written responses being negative.

The findings highlight the fact that the HRM in the hospital complex studied is paying insufficient attention to HR issues. The fundamental failings of the HR department have caused substantial frustration among doctors, providing a significant 'push factor' away from service in the state sector and having a direct impact on doctors' willingness to remain in service at the complex. Only $32 \%$ of the respondents were willing to commit to continue working in this environment, while $45 \%$ indicated a desire to leave and $23 \%$ were undecided. The impact of poor HRM revealed in this study can therefore only perpetuate the staffing problems that plague the institution.
HRM in the health sector is known to be an enormous challenge, ${ }^{[1]}$ and although many of the problems in this study were attributed to the staff in the HR department, the influence of system inefficiencies cannot be discounted. HR staff in the hospital complex may in fact be hamstrung, with little ability to enhance their productivity and as frustrated as doctors are by their limited capability. An investigation into this aspect of HR may warrant further research, the results of which could potentially significantly enhance our understanding of public health HRM.

If $\mathrm{HR}$ is going to play an active part in retaining doctors at the complex studied, substantial improvement in all areas is urgently needed. As members of Generation Y come to predominate in the workforce, managing, motivating and, most importantly, retaining these health professionals is set to become increasingly challenging. HRM improvement is therefore critical, not only to alleviate immediate staffing concerns but also to prepare for a diverse generational blend of HCWs.

\section{Conclusion}

This study has revealed that unacceptable HRM practices appear to be perpetuating the shortage of doctors and adversely affecting retention of key health personnel. The link between sound HRM and doctor retention is clearly evident, as is the importance of urgently addressing HRM shortcomings.

South African public hospitals need to strive to become 'magnet hospitals, ${ }^{[11]}$ attracting doctors who want the opportunity to gain clinical experience. However, this will not happen unless the doctors working in these hospitals know that highly trained HR staff members who are passionate about their work are successfully attending to all their administrative concerns.

\section{References}

1. Kahn T. Red lights flash for Eastern Cape Health. 8 August 2012. http://www.bdlive.co.za/ articles/2012/05/31/red-lights-flash-for-eastern-cape-health;jsessionid=8B0AE735CF274F6E48F517B 0E6DBDAD.present2.bdfm (accessed 1 February 2013).

2. De Waal M. Eastern Cape's so-called health system: In dire need of resuscitation. 27 June 2012. http:// www.dailymaverick.co.za/article/2012-06-27-eastern-capes-so-called-health-system-in-dire-need-ofresuscitation/\#.UoZCq2thiSM (accessed 1 February 2013).

3. National Department of Health. Strategic Plan 2010/11-2012/13. Pretoria: NDoH, 2010. http://www. mm3admin.co.za/documents/docmanager/2D5ED792-878C-4371-9575-8281A96BBB26/00023294. pdf (accessed 8 October 2013).

4. SABC News. E Cape doctor shortage prompts Motsoaledi to intervene. 31 May 2012. http://www.sabc. co.za/news/a/df29a6004b70e6e8906498a9f8f2aadf/E-Cape-doctor-shortage-prompts-Motsoaledi-tointervene-20120531 (accessed 8 October 2013).

5. Human Resources for Health South Africa. HRH Strategy for the Health Sector: 2012/13 - 2016/17. Pretoria: NDoH, 2012. http://www.info.gov.za/view/DownloadFileAction?id=152486 (accessed 8 October 2013)

6. Padarath A, Chamberlain C, McCoy D, et al. Health personnel in southern Africa: Confronting maldistribution and brain drain. Harare: Network for Equity in Southern Africa, 2003.

7. Kotzee T, Couper ID. What interventions do South African qualified doctors think will retain them in rural hospitals of the Limpopo province of South Africa? Rural Remote Health 2003;6(3):581. http:// www.rrh.org.au/publishedarticles/article_print_581.pdf (accessed 8 October 2013).

8. Willis-Shattuck M, Bidwell P, Thomas S, et al. Motivation and retention of health workers in developing countries: A systematic review. BMC Health Serv Res 2008;8(1):247. [http://dx.doi.org/10.1186/14726963-8-247]

9. Cennamo L, Gardner D. Generational differences in work values, outcomes and person-organization values fit. Journal of Managerial Psychology 2008;23(8):891-906.

0. Erickson T. Plugged In: The Generation Y Guide to Thriving at Work. Boston: Harvard Business School Publishing, 2008:1-278.

1. Buchan J. What difference does ('good') HRM make? Hum Resour Health 2004;2(1):6. [http://dx.doi. org/10.1186/1478-4491-2-6]

Accepted 22 November 2013 